\title{
Executive dysfunction in early Alzheimer's disease
}

\author{
G Binetti, E Magni, A Padovani, S F Cappa, A Bianchetti, M Trabucchi
}

\begin{abstract}
Twenty five patients with probable mild Alzheimer's disease were assessed for deficits in executive functioning and the impact of these deficits on performance in other neuropsychological domains. The Wisconsin card sorting test, the release from proactive interference paradigm, the verbal fluency test, and the Stroop test were adopted to classify patients with $(A D+)$ and without $(A D-)$ executive deficits. Seven of the patients showed an impairment in executive function (AD+), defined as a performance below the cut off score in at least two of these tests. There were no significant differences in clinical assessments, demographic features, or other cognitive functions between patients.

Executive dysfunction may be an early additional feature in a subgroup of patients with mild Alzheimer's disease. Impairment on frontal lobe tests does not seem to be related to the severity or duration of disease, or to a different pattern of impairment in other cognitive domains.
\end{abstract}

(F Neurol Neurosurg Psychiatry 1996;60:91-93)

Keywords: Alzheimer's disease; executive function

Alzheimer's disease is characterised by impairment of multiple memory related systems. In addition patients with Alzheimer's disease have disturbances in several other cognitive domains such as language, visuospatial skills, praxis, and abstraction. ${ }^{1}$ In addition to clinical, epidemiological, biological, and neuroimaging findings, the evidence of distinct profiles of cognitive deficits has led some authors to suggest the existence of heterogeneous subtypes of patients with Alzheimer's disease. ${ }^{12}$ For example, there is evidence that in individual patients the presenting symptom may not be the usual memory loss but one or more of a number of deficits involving other cognitive functions. As there is growing evidence, particularly from imaging studies, suggesting a considerable involvement of the frontal cortex in Alzheimer's disease, ${ }^{3}$ study of executive dsyfunction is essential to the understanding of heterogeneity of the disease.

Various aspects of memory and learning have been related to frontal lobe dysfunction. It has been suggested that in addition to more direct involvement with selected aspects of memory, such as remote memory, confabulation, and memory for temporal sequences, the frontal lobes play a strategic part as a "cognitive mediation" system in the encoding and retrieval of memories. ${ }^{4}$ Frontal lobe involvement in the clinical heterogeneity of Alzheimer's disease, however, has not been fully investigated and it is still unclear whether frontal lobe related neuropsychological impairments are integral to Alzheimer's disease in the early phase, and whether they are associated with a differential pattern of neuropsychological impairment. The aim of this study was to evaluate executive function in patients with mild Alzheimer's disease and to investigate the relation between executive dysfunction and performance in other neuropsychological domains such as language, memory, attention, abstract reasoning, and visuospatial abilities. For this purpose, the Wisconsin card sorting test, ${ }^{5}$ the release from proactive interference, ${ }^{6}$ the verbal fluency test, ${ }^{7}$ and Stroop test ${ }^{8}$ were adopted to classify patients with $(\mathrm{AD}+)$ and without $(\mathrm{AD}-)$ executive deficits.

\section{Subjects and methods}

All patients included in this study were evaluated in the Alzheimer's disease unit at $S$ Couore Fatebenefratelli Hospital in Brescia, Italy, and were drawn from a consecutive series of patients included in a longitudinal programme on mild Alzheimer's disease (MADI project).

Twenty five consecutive patients, affected by probable Alzheimer's disease according to currently accepted clinical criteria, ${ }^{9}$ and with a questionable or mild form of dementia (clinical dementia rating (CDR) 0.5 or 1$)^{10}$ were included in the study. All patients had CT or MRI to exclude other possible aetiologies of dementia.

Twenty five normal elderly subjects, either correlated volunteers or spouses of patients, were also included in the study. History of alcoholism, drug abuse, learning disabilities, and serious neurological or psychiatric illnesses were considered as exclusion criteria. Written informed consent was obtained from all subjects (patients and controls), or care- 
givers where appropriate. Patients and controls were assessed on the geriatric depression scale (GDS)" to exclude subjects with severe depressive symptoms (GDS score $>20$ ). The mini mental state examination (MMSE) ${ }^{12}$ was given to characterise the global cognitive level.

\section{NEUROPSYCHOLOGICAL ASSESSMENT}

The following neuropsychological tests were given to both groups (for details of tests see Binetti et $a l^{1}$ ).

Short term memory was assessed by auditory-verbal forward digit span and visuospatial span (Corsi's block tapping test). Episodic memory was tested with the logical memory test (recall of a short story) and with the 20 minutes delayed recall of the Rey complex figure. A 30 item version of the Boston naming test provided a measure of naming and semantic memory. Remote memory was assessed with the Q60 questionnaire. The Street test and the copy of the Rey figure were used to assess visuospatial abilities. The Raven's coloured progressive matrices test, the attentional matrices test, and the token test were also included in the neuropsychological battery.

"Executive" function was evaluated by the Wisconsin card sorting test (WCST), ${ }^{5}$ PFL verbal fluency test, ${ }^{7}$ Stroop test, ${ }^{8}$ and the release from proactive interference paradigm. ${ }^{6}$

The WCST is a problem solving task that measures the ability to identify abstract categories and shift cognitive set. A shortened

Table 1 Performance of patients with $(A D+)$ and without $(A D-)$ executive functions deficits

\begin{tabular}{|c|c|c|c|}
\hline & $\begin{array}{l}A D- \\
(n=18) \\
(\text { mean }(S D))\end{array}$ & $\begin{array}{l}A D+ \\
(n=7) \\
(\text { mean }(S D))\end{array}$ & $\begin{array}{l}\text { No of patients } \\
\text { below the cut off (\%) }\end{array}$ \\
\hline \multicolumn{4}{|l|}{ Demographic data: } \\
\hline Age $(y)$ & $72 \cdot 1(9 \cdot 5)$ & $73 \cdot 7(6 \cdot 9)$ & - \\
\hline Education (y) & $7 \cdot 4(4 \cdot 1)$ & $5 \cdot 7(1.6)$ & - \\
\hline $\mathrm{M} / \mathrm{F}$ & $3 / 15$ & F7 & - \\
\hline CDR $(0.5 / 1)$ & $4 / 14$ & $3 / 4$ & - \\
\hline MMSE & $21 \cdot 5(2 \cdot 2)$ & $21 \cdot 4(2 \cdot 4)$ & - \\
\hline Duration of illness (months) & $30 \cdot 7(18.9)$ & $36 \cdot 8(24 \cdot 1)$ & - \\
\hline Geriatric depression scale & $12 \cdot 0(7 \cdot 6)$ & $10 \cdot 4(6 \cdot 8)$ & - \\
\hline \multicolumn{4}{|l|}{ Tests: } \\
\hline Verbal fluency $(\mathrm{PFL}) \dagger$ & $17 \cdot 5(7 \cdot 9)$ & $10 \cdot 0(9 \cdot 4)$ & $3(12)$ \\
\hline Wisconsin card sorting test: & & & \\
\hline $\begin{array}{l}\text { Index of perseveration } \\
\text { Stroop test interference }\end{array}$ & $\begin{array}{r}0.3(0 \cdot 14) \\
-3 \cdot 1(12 \cdot 7)\end{array}$ & $\begin{aligned} & 0.5(0.17)^{\star} \\
- & 3.8(9.4)\end{aligned}$ & $\begin{array}{l}7(28) \\
5(29)\end{array}$ \\
\hline $\begin{array}{l}\text { Release from proactive interference } \\
\text { (block 5-block 4) }\end{array}$ & $1 \cdot 5(3 \cdot 1)$ & $-0.8(3 \cdot 0)^{\star}$ & $12(48)$ \\
\hline
\end{tabular}

$\star \mathrm{P}<0.05$.

tScores are not corrected for age and education.

$\mathrm{CDR}=$ Clinical dementia rating.

Table 2 Performance of patients with Alzheimer's disease with $(A D+)$ and without $(A D-)$ frontal lobe dysfunction on tests of memory, language, attention, abstract thinking, and visuospatial abilities

\begin{tabular}{lcc}
\hline Test & $\begin{array}{c}A D- \\
(n=18) \\
(\text { mean }(S D))\end{array}$ & $\begin{array}{c}A D+ \\
(n=7) \\
(\text { mean }(S D))\end{array}$ \\
\hline Digit span & $5 \cdot 3(1 \cdot 1)$ & $4 \cdot 7(0 \cdot 7)$ \\
Corsi test & $4 \cdot 7(0 \cdot 9)$ & $4 \cdot 4(0 \cdot 9)$ \\
Logical memory test & $2 \cdot 5(3 \cdot 5)$ & $2 \cdot 6(2 \cdot 0)$ \\
Rey figure 20 minute recall & $1 \cdot 5(3 \cdot 4)$ & $0 \cdot 9(2 \cdot 4)$ \\
Token test & $28 \cdot 0(3 \cdot 1)$ & $29 \cdot 0(4 \cdot 0)$ \\
Boston naming test & $13 \cdot 7(5 \cdot 1)$ & $12 \cdot 8(8 \cdot 2)$ \\
Attentional matrices & $30 \cdot 3(8 \cdot 7)$ & $28 \cdot 5(8 \cdot 4)$ \\
Raven 36 PM colour & $18 \cdot 8(5 \cdot 2)$ & $17 \cdot 5(3 \cdot 5)$ \\
Rey figure copy & $24 \cdot 2(8 \cdot 5)$ & $19 \cdot 7(9 \cdot 7)$ \\
Street test & $4 \cdot 4(2 \cdot 0)$ & $5 \cdot 0(2 \cdot 0)$ \\
Q60 & $21 \cdot 2(5 \cdot 1)$ & $14 \cdot 9(8 \cdot 3)$ \\
\hline
\end{tabular}

${ }^{\star}$ A 30 items version was used. version of $\mathrm{WCST}^{5}$ with 64 cards was adopted, computing an index of perserveration (IP; number of errors/number of perseveration). The verbal fluency for letters (PFL) was assessed by recording the number of words produced in the course of one minute for each letter. ${ }^{7}$ The Stroop colour word test ${ }^{*}$ is an executive task for the assessment of the ability to change perceptual sets to conform to changing task requirement. The interference score (IS) was calculated by subtracting the predicted colour word score from the raw colour word scores. The higher the resultant score, the less susceptible the patient is to interference. The release from proactive interference (RPI) paradigm was evaluated using the Wickens' ${ }^{\prime}$ modification of the Peterson and Peterson ${ }^{13}$ distractor technique according to Freedman and Cermak. ${ }^{1+4}$ The stimuli, consisting of five trials of words triads grouped in four blocks, were presented on a $23 \times 18 \mathrm{~cm}$ monitor. After the presentation of each triad subjects were asked to count backwards from a random number as rapidly as possible, to preclude rehearsal of the triad. After counting for 10 seconds, the patient was asked to recall the three words he had just read. Each block of five trials consisted of the presentation of four triads of words from the same semantic category, followed by a fifth triad of words from a different semantic category (shift condition (SC)). Each block consisted of high lexical frequency words from four categories taken from Battig and Montague Connecticut category norms..$^{15}$ The categories were, in sequence, animals, fruits, colours, and vegetables. The SC effect was calculated by subtracting the fourth trial score from the score of each fifth trial throughout the blocks.

As an arbitrary cut off value to identify patients with prominent executive dysfunction, we adopted the criterion of a score $1 \mathrm{SD}$ below the controls' mean on at least two out of the four measures of frontal lobe function (IP, PFL, IS, SC).

\section{Results}

According to the described cut off, we identified two subgroups of patients with Alzheimer's disease: seven patients (AD+) were considered to show executive dysfunction and 18 patients $(\mathrm{AD}-)$ not. Table 1 shows the number of patients below the cut off for each test.

The $\mathrm{AD}+$ and $\mathrm{AD}$ - groups were comparable in terms of age, education, sex, and depressive synptoms (table 1). There was no difference between $\mathrm{AD}+$ and $\mathrm{AD}-$ patients for MMSE score and duration of illness.

As shown in table 2, we did not find a significant difference between $\mathrm{AD}+$ and $\mathrm{AD}$ - patients on neuropsychological tests of memory, language, attention, abstract thinking, or visuospatial abilities.

\section{Discussion}

Although the deterioration of cognitive function is considered to be widespread in 
Alzheimer's disease,${ }^{1}$ frontal lobe involvement in the clinical presentation of the disease has not been investigated in detail. Thus it is still unclear whether executive dysfunction is an integral component of early Alzheimer's disease or rather characterises later stages of the disease.

This study showed that executive dysfunction may be an early manifestation of Alzheimer's disease. In fact seven out of 25 patients were found to be impaired on tests measuring executive function, supporting previous findings in Alzheimer's disease. ${ }^{16} 17$

To evaluate whether the presence of executive dysfunction could be related to variables such as age, education and duration of the illness, the $\mathrm{AD}+$ and $\mathrm{AD}$ - groups were compared. There were no major differences between the groups.

One of our aims was to investigate whether a deficit in executive functioning in mild Alzheimer's disease was associated with a different pattern of neuropsychological impairment. No significant cognitive differences were found between the $\mathrm{AD}+$ and $\mathrm{AD}$ groups using a complete neuropsychological battery. This finding suggests that executive dysfuncton, as defined in this study, has little impact on the performance of tasks measuring other cognitive domains such as language, visuospatial function, and memory.

The present data may reflect the involvement of the frontal cortex in the early phase of disease in a subgroup of patients.

Studies with PET and SPECT have indicated that an anterior involvement, although not typical, can be seen in the early phase of disease. ${ }^{318}$

The pattern of the impairment seems to be clearly differentiated from the clinical picture in patients with suspected frontotemporal dementia, ${ }^{19}$ given the lack of the behavioural features of the "frontal lobe syndrome" which are often present in this condition.

Taken together, these findings seem to support the existence of a subgroup of patients with mild Alzheimer's disease who have additional neuropsychological executive deficits unrelated to impairment of other cog- nitive domains, and suggest the possible involvement of the frontal lobe in early stages of the disease.

We thank the two anonymous reviewers for their helpful suggestions.

1 Binetti G, Magni E, Padovani A, Cappa SF, Bianchetti A, Trabucchi $M$. Neuropsychological heterogeneity in mild Alzheimer's disease. Dementia 1993;4:321-6.

2 Mayeaux R, Stern Y, Spanton S. Heterogeneity in dementia of Alzheimer's type: evidence of subgroups. Néurologv $1985 ; 35: 453-61$

3 Grady CL, Haxby B, Horwitz M, Sundaram M, Berg G. Shapiro $M$, et al. Longitudinal study of the early neuropsychological and cerebral metabolic changes in dementia of the Alzheimer's type. F Clin Exp Neuropsychol 1988;10:576-96

4 Warrington EK, Weiskrantz L. Amnesia: a disconnection syndrome? Neuropsychologia 1980;20:233-48.

5 Berg EA. A Simple objective test for measuring flexibility in thinking. F Gen Psychol 1948;39:15-22.

6 Wikens DD. Encoding categories of words: an empirical approach to meaning. Psychol Rev 1970;77:1-15.

7 Novelli G, Papagno C, Capitani E, Laiacona M, Vallar G, Cappa SF. Tre test clinici di ricerce e produzione lessicale: Taratura su soggetti normali. Archivio di Psicologia, Neurologia e Psichiatria 1986;47:477-506.

8 Golden CJ. Stroop color and word test. Chicago, Stoeltig Company, 1978 .

9 McKhann G, Drachman D, Folstein M, Katzman R, Price $D$, Stadlan EM. Clinical diagnosis of Alzheimer's disease: report of the NINCDS-ADRDA Work Group under the auspices of Department of Health and Human Services Task force of Alzheimer's disease. Neurology 1984;34:939-44.

10 Hughes CP, Berg L, Danzinger WL, Coben LA, Martin LA. A new clinical scale for the staging of dementia. Br F Psychiatry 1982;140:566-72.

11 Yesavage JA. Brink TL, Rose TL, Andrey M. Geriatric depression rating scale: comparison with other self report and psychaitric rating scales. In: Crook T, Ferris S, Bartus R, eds. Assessment in geriatric psychoparmacology: New Canaan, 1983.

12 Folstein MF, Folstein SE, McHugh PR. Mini mental state. 7 Psychiatr Res 1975; 12:189-98.

13 Peterson LR, Peterson MJ. Short-term retention of individual items. F Exp Psychol 1959;58:193-8.

14 Freedman M, Cermak LS. Semantic encoding deficits in frontal lobe disease and amnesia. Brain Cogn 1986;5 108-14.

15 Battig WF, Montague WE. Category norms for verbal items in 56 categories: a replication and extension of the Connecticut category norms. Foumal of experimental Psychology Monographs 1969;80:1-46.

16 Kopelman MD. Frontal dysfunction and memory deficits in the alcoholic Korsakoff syndrome and Alzheimer-type dementia. Brain 1991;114:117-34

17 Bhutani GE, Montaldi D, Brooks DN, McCulloch J. A neuropsychological investigation into frontal lobe involvement in dementia of the Alzheimer type. Neuropsychology 1992;6:211-24.

18 Foster ML, Chase TN, Fedio P, Patronas NJ, Brooks RA Alzheimer's disease: focal cortical changes shown by positron emission tomography. Neurology 1983;33 $961-5$.

19 Brun A, Englund B, Gustafson L, Passant U, Mann DMA Neary D, Snowden JS. Clinical and neuropathological criteria for frontotemporal dementia. 7 Neurol Neurosurg Psychiatry 1994;57:416-8. 